\title{
La Corona en el régimen político de 1876
}

\author{
MARÍA ÁNGeLES LARIO GONZȦLEZ
}

El papel de la Corona como Institución dentro del sistema político instaurado por la Constitución de 1876 , es un tema tradicionalmente desatendido por los historiadores de este período ${ }^{1}$ a diferencia de lo que ocurre con la propia persona del rey Alfonso XIII. Ciertamente la Corona tiene su sitio entre los poderes establecidos constitucionalmente, y es necesario delimitarlo. No sólo la Constitución habla de ella, sino que también existen unas prácticas establecidas, un "espíritu», unas costumbres entre los hombres de la Restauración, que de modo aún más claro nos indican las verdaderas dimensiones de las tareas que se le encomendaron. Descubrir cuáles fueron efectivamente estas tareas y dejarlas establecidas; averiguar cómo la Corona ejerció la prerrogativa regia, nos ha de ayudar a entender la causa del fracaso de éste Régimen político que tantas consecuencias acarreó.

El contexto es una monarquía constitucional o doctrinaria, de ningún modo democrática, y que se reserva para sí un amplio espacio de poder; de ahí que sea importante conocer de qué modo ejerció el mismo, a través fundamentalmente de la denominada prerrogativa regia que era, sin duda, de sus facultades la que más frecuentemente tenía que aplicar, puesto que entraba en juego en los momentos de crisis de gabinete ya que abarcaba la facultad de nombrar y separar libremente a los ministros,

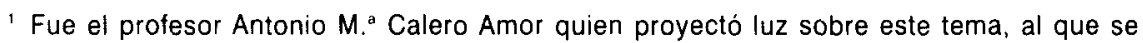
dedicó hasta su temprana muerte. Bajo su magisterio nos iniciamos en el estudio de las crisis políticas y el papel de la Corona.

Entre sus obras: “El papel político de la Corona en el reinado de Alfonso XIII. Criterios para una revisión"; en España, 1898-1936. Estructuras y cambio, 1984, "Los precursores de la Monarquía democrática", en La España de la Restauración, 1985. "La prerrogativa regia en la Restauración". Teoría y práctica (1875-1902), en La Corona en la H. ${ }^{a}$ constitucional española. 1987. "Monarquía y democracia en las cortes de 1869". Selección y estudio preliminar. 1987. «Estudios de Historia». 1988. 
conceder la disolución de Cortes o la suspensión de sesiones y, en definitiva, de controlar en última instancia los actos del ejecutivo con la posibilidad de negar su firma a los reales decretos.

Aparte del estudio exhaustivo de cada crisis política que ayude a clarificar de una vez por todas el carácter de la actuación del Monarca en el momento más trascendental de su intervención política, sería interesante conocer la interpretación que los políticos de la época hacen de la actividad de la Corona; de alguno de ellos, sin duda, se podrá conseguir y posiblemente llegar a conocer en general cómo entendian su propio papel dentro de este tipo de monarquía.

Para la correcta comprensión del tema hay que comenzar por subrayar diferentes aspectos del mismo que hay que tener presentes en todo momento:

Al principio ya se dijo que ésta no era una Monarquía democrática, y esto se hace evidente en la negación de hecho de la soberanía popular: en primer lugar la Constitución la decreta y sanciona el Rey "en unión y de acuerdo con las Cortes". Para nada se habla de la Soberanía. El Rey tiene iniciativa legal en la misma medida que los Cuerpos legisladores; nombra y separa libremente a sus ministros. En fin, se establece la cosoberanía del Rey y la Nación y, sin embargo, el Rey es irresponsable porque la responsabilidad queda transferida a los ministros que para serlo tienen que gozar de la confianza del Parlamento y de la Corona. Este último es un dato de lo más significativo, porque sin entrar de momento en más análisis y a primer golpe de vista a cualquiera se le ocurre que de ser aquéllos dos poderes totalmente independientes, habrían de entrar constantemente en lid y uno necesariamente tendría que ceder. La relación que deba existir entre los ministros y el Rey es un tema oscuro, como lo es la esfera de poder de ambos en la práctica; aquí es donde radica el punto neurálgico del problema: en la sutil relación establecida entre el Rey y sus ministros, quedando por medio y como cabeza visible la figura del Presidente del consejo.

Según la doctrina comúnmente admitida, la Corona quedaba instituida como poder moderador: debería restablecer la armonía entre las Cortes y el Gobierno, debería interpretar la opinión pública, y para ello debía utilizar la regia prerrogativa, antes mencionada, de tal modo que estando en manos del ejecutivo la creación de los Parlamentos, y en manos del Rey la formación de los Gobiernos, se transfería a éste toda la máquina política del régimen, incluido el personal político, que se sabía dependiente de la confianza del Rey; es decir, en la práctica más que moderador era el poder más eficaz y con la mayor capacidad de decisión; esto se 
hace evidente en el consejo que Natalio Rivas ${ }^{2}$ le da a Santiago Alba por si quiere acceder al poder: debería despejar las dudas que sobre su persona tuviera el Monarca porque «en un momento dado puede venir una coyuntura favorable y no tener al Rey».

Así pues, la legitimidad política durante la Restauración se encontraba en la confianza otorgada por el Monarca, ya no sólo en base a unos criterios preestablecidos: Monarquismo demostrado, unión del partido, aceptación del turno, etc.; sino también por la confianza personal de aquél que en cada momento portaba la Corona. Bien es cierto que existía lo que Antonio María Calero llamó «las reglas no escritas» de actuación entre el Rey y sus ministros que implicaban el evitar el capricho personal, el exclusivismo de un partido, no conceder dos veces seguidas el decreto de disolución al mismo partido; pero, salvando las dos últimas, la primera era algo muy difícil de demostrar cuando se trataba de escoger ministros, y quizás de evitar, siendo que las Cortes no eran realmente representativas y no podían ser reflejo de la opinión pública y por lo tanto determinantes en la formación del Gobierno; y los jefes de partidos solían ser tremendamente respetuosos con las decisiones regias, o al menos lo suficiente para procurar dejar en la sombra cualquier atisbo de iniciativa personal del Rey; así queda demostrado en repetidas ocasiones en la correspondencia intercambiada entre el Rey y el Presidente del Gobierno de turno: era una preocupación constante el intentar evitar cualquier sospecha por parte de la opinión pública sobre iniciativas personales del Monarca. Esto ya indica lo cerca que se encontraba en todo momento esa posibilidad, y el "talón de Aquiles" de un régimen que ni quiso ni probablemente hubiera sabido salvar de una vez por todas ese escollo que le estaba impidiendo caminar decididamente hacia adelante.

Visto esto, no sorprende que las crisis sean especie de largas negociaciones para el cambio a las que no es ajeno el Rey y cuya explicación final suele distar mucho de la realidad: En una carta de Moret a don Alfonso de Aguilar para que informe al Monarca se dice que el Presidente (Sagasta) había aceptado resueltamente "lo sugerido" y que era el momento de crisis aunque opinaba que no debería plantearse hasta finales de marzo (la carta es de enero) porque, entre otras cosas "como habría que buscarla explicación, tal vez se supusiera que la Corona entraba por algo en el cambio y se perjudicaría a su imparcialidad e irresponsabilidad, que el Presidente quiere cubrir y garantizar ante todos ${ }^{3}$. En este terreno

\footnotetext{
2 Político de segundo orden pero que siguió muy de cerca los acontecimientos políticos y dejó unas detalladas Memorias y otra serie de documentos que forman su archivo personal. La cita en Memorias, 13 de noviembre de 1917.

${ }^{3}$ Archivo de Palacio. Carta de Moret a don Alfonso de Aguilar, 18 de enero de 1902.
} 
Silvela fue más claro; también en estas fechas y en un discurso en el Congreso vino a decir: "lo que indudablemente significaria un retroceso, Ilevaría consigo riesgos considerables, atacando el fundamento capital del sistema monárquico-representativo, que es la irresponsabilidad del Monarca, sería que su juicio y su capricho se sustituyeran a las fuerzas colectivas de los partidos, y que determinaciones, por fundadísimas que ellas fueran y criterios particulares, por altos y elevados que los consideremos, vinieran a reemplazar a las fuerzas de los partidos, a la opinión de los partidos, a las colectividades, en fin, que determinan nuestra vida política". Era evidente el peligro ya en 1902 y se consideraba urgente sustraer el criterio del poder Real de la intervención directa, del juicio individual, colocándolo sobre los hombres públicos; pero esto no bastaba con decirlo o advertirlo, había que poner algún remedio eficaz para que el Presidente del Consejo no se viera en la casi obligación de cubrir con su firma los deseos del Rey (en este caso de la Regente María Cristina), puesto que cuando esto no se hacía se llegaba a discutir en el Parlamento la situación en que quedaba la Corona y, evidentemente esta fisura era aprovechada por los enemigos del Régimen, los republicanos, para poner en duda o negar rotundamente la irresponsabilidad del Jefe del Estado, base misma de todo el sistema.

Por su parte la figura del Presidente del Consejo era vista por algunos como peligrosa para el poder del Rey e incluso se habla de "abusivas facultades dictatoriales» ante la postura defendida en el Parlamento por Silvela de que aquél pudiera remodelar el Gabinete sin dar cuenta de estas crisis parciales; Torres Cabrera llega a presentar en el Senado una proposición de Ley para que cada ministro fuera una figura independiente y responsable y seguramente en despacho directo con el Monarca, haciendo innecesaria la figura del Presidente cuyas atribuciones deberían quedar reducidas a las de puro procedimiento, y asi se lo expresa directamente por carta al Monarca; había, pues, en la realidad una lucha por el poder entre la Corona y el Presidente del Consejo, que era una lucha entre el pasado y el futuro y que durante el régimen de la Restauración nunca se llegó a resolver claramente, jugando constantemente con el equívoco y zafándose así unos y otros de las responsabilidades.

Evidentemente esta situación también beneficia a los políticos que aprenden a convivir y a aprovecharse de ella de tal modo que sólo buscan en el Palacio la consecución del poder y no dudaban en invocar la regia prerrogativa para conseguirlo; unas veces acusando al turnante de tenerla secuestrada y casi siempre reflejando en lo que acusan a los demás, los vicios que eran generales y que todos sabían que podían ser utilizados: así sucede cuanto Moret, recién caído del gobierno, en agosto de 1906 le escribe a Natalio Rivas criticando la actitud del Presidente del Consejo 
(López Domínguez) que, según él, no duda en comprometer al Rey para dar las apariencias de escudar su conducta. El hecho es que todos los políticos viven pendientes de la "temperatura" del Palacio, siempre preocupados por posibles intrigas o confidencias que pudieran incidir en el ánimo del Monarca, derivando en una especie de personalismo alrededor del mismo que acabó dejando sobre sus hombros toda la responsabilidad de los acontecimientos; así es que, cuanto más fervientemente prometían aquéllos salvar la irresponsabilidad regia, más iba quedando ésta al descubierto. De hecho Antonio Maura, ejemplo de político agraviado en este ambiente político tan personalista, viene a reflejar hasta qué punto llega - o en el mejor de los casos puede llegar - la mano del Rey al decir “media un abismo entre aquel alto y noble influjo del Rey sobre la organización política de las verdaderas fuerzas sociales, y su ingerencia en las discordias internas de los partidos", al exponer las razones por las cuales opinaba en contra de la disolución de Cortes que pretendía Moret con el objeto de reforzar el partido liberal con su propia jefatura ${ }^{4}$; vemos que la Corona no estaba libre ni de presiones ni de críticas, incluso por un político monárquico al que, eso sí, en su opinión se le había roto «el muelle real»; tanto es así que ya en 1917 se dice que el Rey ha perdido enorme terreno, que aún perdería más, que se habla de él sin respeto alguno y que incluso los militares no se recatan para censurarlo en términos irrespetuosos.

Se puede argüir que habría sido fácil para la clase política contrarrestar el poder del Rey - disolver Cortes, negar la firma a los decretos, etc.utilizando el arma de la dimisión y la explicación clara de las causas que la originaron, es decir, renunciar a que la Corona fuera el punto de apoyo de su poder; pero entonces idónde lo iban a buscar?: tendrían que acudir al Parlamento - representación de caciques en su mayoría- y a los electores, y para eso no estaban preparados; ni tenian organizaciones de partidos capaces de llevarlo a cabo, ni de ningún modo les resultaba más fácil acceder al poder por esa vía en una sociedad donde las exigencias eran cada vez mayores, y donde, aquéllos que tenian cierta conciencia política entre la gran mayoría, se agrupaban en torno al partido socialista o a las organizaciones anarquistas (el partido reformista nacería para atender a una naciente clase media de negocios e intelectuales); entonces era evidente que los partidos del turno eran organizaciones obsoletas que sólo vivían del aliento real en base a un sistema político que para mantenerlo necesitaba exageradas dosis de sutileza para no denunciarse a sí

${ }^{4}$ Archivo de Palacio. Consejo de Maura, 10 de junio de 1906. 
mismo, es decir, para no hacer recaer sobre la Corona -pretendidamente irresponsable - todo el peso de la responsabilidad que acumulaban sus ministros.

Esta situación daba lugar a que en los Consejos de Ministros se discutiera más o menos frecuentemente los «derechos» del Rey para intervenir en los asuntos de gobierno: podía llegarse a una división de opiniones sobre si el Rey debía conocer previamente o no una comunicación a un gobierno extranjero: sólo Romanones opinaba en contrario; para Natalio Rivas era, sin embargo, «un elementalísimo deber constitucional... no darle curso hasta que lo conociese el Soberano, que podía incluso no conformarse con ella y debía, como es justo, tener libertad de acción para otorgar su confianza a otro gobierno" ${ }^{5}$. Si Romanones podía basar su actitud en el espíritu o práctica constitucional, Natalio Rivas tenía presente lo que la Norma Fundamental dice: el artículo 52.5 establece que corresponde al Rey dirigir las relaciones diplomáticas (y comerciales) con las demás potencias; y el artículo 50 «la potestad de hacer ejecute las leyes reside en el Rey, y su autoridad se extiende a todo cuanto conduce a la conservación del orden público en lo interior y a la seguridad del estado en lo exterior». Si la letra fuera literalmente aplicada, Romanones nunca habría puesto en duda la conveniencia de que el Rey conociera previamente la notificación a Alemania durante la guerra mundial, que era de lo que se trataba en el Consejo de Ministros citado.

Ya se dijo que hacía falta mucha sutileza para mantener en pie este edificio político porque los propios sustentadores, los políticos, no dudaban en echar piedras sobre su tejado cuando el ambiente de Palacio no les era favorable: así, a raíz de un posible desaire a Santiago Alba por parte del Alfonso XIII, Natalio Rivas comenta que «no sabe que los tiempos en que mirar o no mirar el Rey a un hombre político era el ser o el no ser, han pasado ya".

Todo esto nos lleva a considerar a la Corona como instrumento del que se valen las oligarquías gobernantes para legitimar el modelo de estado y sociedad que pretendían, primero organizar y luego mantener, elevándola al difícil papel de árbitro que aplique las reglas de juego y dirima los conflictos, pero preferiblemente sólo en la medida en que lo exijan los intereses de los partidos del turno, mejor dicho de los oligarcas de estos partidos.

Hay que dejar constancia entonces, de que esta Institución había sido colocada en la clave del edificio de la Monarquía restaurada, de tal manera

${ }^{5}$ Rivas, Natalio, Memorias, 10 de agosto de 1918. 
que de una forma u otra tendría que verse comprometida en las soluciones que el régimen iba buscando para mantenerse, y que al final contribuyó a su propia caída, de un modo ciertamente lógico, puesto que no habia sido previamente reformada y encauzada hacia posibles vías democráticas; en este sentido ya en 1913 Melquíades Álvarez pensaba que habría que reformar el régimen de relaciones entre el Presidente y el Rey, para que el Parlamento tuviera verdaderas funciones de poder cosoberano.

Resulta así evidente que el final de la Monarquía se encontraba en germen en el propio papel que se le había asignado dentro del sistema político de 1875 y que los hombres encargados de mantenerlo no supieron o no pudieron evitarlo. 